\title{
Facial Nerve Function after the Extended Translabyrinthine Approach
}

\author{
Mia E. Miller ${ }^{1}$ Bill Mastrodimos ${ }^{2}$ Roberto A. Cueva ${ }^{3}$ \\ ${ }^{1}$ Department of Otolaryngology, University of California at \\ Address for correspondence Mia E. Miller, MD, Department of \\ San Francisco, San Francisco, California, United States \\ 2 Department of Neurosurgery, Kaiser Permanente San Diego, \\ San Diego, California, United States \\ ${ }^{3}$ Department of Otolaryngology, Kaiser Permanente San Diego, \\ San Diego, California, United States \\ Otolaryngology, University of California at San Francisco, 2233 Post \\ Street, San Francisco, CA 94115, United States \\ (e-mail: miamiller001@gmail.com). \\ J Neurol Surg B 2015;76:1-6.
}

\begin{abstract}
Keywords

- facial paralysis

- meningioma

- petroclival junction

- cerebellopontine angle

Objective To evaluate facial nerve function after excision of petroclival/anterior cerebellopontine angle (CPA) meningiomas by the extended translabyrinthine (EXTL) approach and compare these with outcomes after the transcochlear and transotic approaches.

Design Retrospective chart review.

Setting/Participants A search of archived surgical cases at a single institution between January 1, 1995, and January 1, 2012.

Main Outcome Measures Facial function measured on the House-Brackmann (HB) scale. Results A total of 16 patients underwent the EXTL approach for primary excision of petroclival meningiomas. Average tumor size was $4.6 \mathrm{~cm}$, and six patients had gross total resection. Average length of follow-up was 36.4 months. Two patients required reoperation for tumor regrowth. Preoperative facial function was HB I or II in all patients with available examinations. Immediate postoperative facial nerve function ranged from $\mathrm{HB}$ I to $\mathrm{HB}$ VI. In patients with an intact facial nerve at surgery, all but one had long-term facial function of HB I or II. A robust response on intraoperative facial nerve monitoring was prognostic of favorable long-term facial function. Facial function declined in some patients after postoperative radiation or revision surgery.

Conclusions The EXTL approach allows excellent exposure of petroclival/anterior CPA lesions and should be favored to improve facial outcomes.
\end{abstract}

\section{Introduction}

The suboccipital/retrosigmoid and translabyrinthine approaches have been used as workhorses for surgical exposure to cerebellopontine angle tumors; however, those tumors involving the anterior cerebellopontine angle/petroclival junction have been historically challenging to access. ${ }^{1}$ The facial nerve limits the anterior view from the posterior fossa, and some tumors require sacrifice of the cochlea and labyrinth (transotic [TO] approach) or

received

August 1, 2013

accepted

November 23, 2013

published online

August 11, 2014

rerouting of the facial nerve (transcochlear [TC] approach for adequate exposure. Whereas the TO approach can be used for smaller tumors extending anteriorly, ${ }^{2}$ the TC approach is required to improve anterior exposure with larger tumors. ${ }^{3}$

The TC approach, first described by House and Hitselberger in $1976,{ }^{4}$ provides wide access to the anterior cerebellopontine angle and petrous apex with minimal brain retraction, ${ }^{5}$ but rerouting of the facial nerve generally leads to an initial complete facial paralysis (House-Brackmann [HB] VI), and

(c) 2015 Georg Thieme Verlag KG Stuttgart · New York
DOI http://dx.doi.org/ 10.1055/s-0034-1368146. ISSN 2193-6331. 
most patients have long-term facial function of HB III or worse. $^{3,6}$

Histologic diagnosis also affects facial nerve outcomes. In their report of 40 patients who underwent TO and TC approaches for cerebellopontine angle and clivus lesions, De la Cruz and Teufert demonstrated that 55\% of all patients had normal facial function postoperatively, but those with meningiomas had only a $20 \%$ incidence of long-term normal facial function. ${ }^{3}$

Given the challenges of accessing the petroclival junction and the particularly difficult task of preserving facial function with meningiomas in this location, the current article aims to describe the utility of the extended translabyrinthine (EXTL) approach to meningiomas in this area. We propose that the EXTL approach facilitates gross total resection of anteriorly based meningiomas and has superior facial nerve outcomes to the TC approach.

\section{Materials and Methods}

The current study was approved by the institutional review board (IRB). A retrospective chart review of meningiomas excised by the EXTL approach at a single skull base referral center was completed including cases from January 1, 1995, to January 1, 2012.

Each case was reviewed for patient characteristics including patient age, tumor size, presenting symptoms, complications, outcomes, and the need for reoperation. The extent of resection was categorized as gross total or subtotal. Facial nerve preoperative, immediate postoperative, and long-term facial functions were recorded, as well as response to intraoperative facial nerve stimulation. The HB grading system was used. ${ }^{7}$

Postoperative radiation therapy was recorded and length of follow-up was calculated as the time from surgery to the date of the most recent facial nerve examination.

\section{Surgical Technique}

For the purpose of this article, we describe the EXTL approach as follows. A standard translabyrinthine approach involves removal of bone from the middle cranial fossa, posterior cranial fossa, and sigmoid sinus dural surfaces. Labyrinthectomy is completed and the internal auditory canal skeletonized in $\sim 270$ degrees of its circumference. The jugular bulb is routinely identified and skeletonized as well. The extended translabyrinthine approach then uses the corridors above and below the internal auditory canal to remove all the bone of the medial aspect of the petrous apex. The internal auditory canal is skeletonized completely leaving the dura intact. Inferiorly the limit is the inferior petrosal sinus, superiorly the superior petrosal sinus, and anteriorly the petroclival junction. Commonly, the posterior two-thirds of the Meckel cave is decompressed in the EXTL approach. The lateral limit of exposure is the petrous carotid artery. This provides anterior access to the pre-mesencephalic and pre-pontine space.

Because petroclival tumors and anterior cerebellopontine angle tumors often displace the facial nerve/cochleovestibular nerve complex posteroinferiorly, this approach leaves the dura of the internal auditory canal intact to help protect the facial nerve during tumor dissection. The cochleovestibular nerve likewise protects the facial nerve in the cerebellopontine angle. If tumor extends into the internal auditory canal, it is the last portion of the tumor to be addressed. This technique avoids the complete mobilization of the facial nerve required in the TC approach.

\section{Results}

A total of 16 patients underwent the EXTL approach for primary excision of meningiomas. One patient had a combination of EXTL and an extreme lateral approach. The mean patient age at surgery was 54.4 years. Average tumor size was $4.6 \mathrm{~cm}$, ranging from 3 to $7 \mathrm{~cm}$ in maximum diameter. All surgeries were primary operations. Overall, 15 of 16 patients were female. Presenting symptoms (-Table 1) included ataxia, headache, weakness of extremities, vertigo, facial weakness, facial pain/hypoesthesia, difficulty swallowing, tinnitus, and hearing loss. The most common presenting symptoms were hearing loss, imbalance/vertigo, and facial numbness (cranial nerve [CN] V dysfunction).

Six patients had gross total tumor resection, and 10 had subtotal resection. Subtotal resection was pursued in cases where tumors extended inferiorly to the foramen magnum, into the Meckel cave, or when the tumor was adherent to the brainstem or other vital structures.

Complications (-Table 2 ) included various cranial neuropathies, reexpansion edema, cerebrovascular accident, and cerebrospinal fluid (CSF) leak. There was one postoperative death due to meningitis. Average length of follow-up was 36.4 months (range: 3-92 months). Representative preoperative and postoperative magnetic resonance imaging (MRI) is shown in -Figs. 1 and 2. Two patients required reoperation for tumor regrowth, and one patient required reoperation for CSF leak. Six patients underwent stereotactic radiation for tumor residua/regrowth.

- Table 3 presents the facial nerve outcomes. Overall, 13 of 16 patients had available preoperative and postoperative facial nerve examinations. Preoperative facial function was HB I or II in all patients with available preoperative data (15 of 16 patients). In two patients, CN VII was cut because it went through the tumor. Immediate postoperative facial nerve function ranged from $\mathrm{HB}$ I to $\mathrm{HB}$ VI. In patients with an intact facial nerve at surgery, all but one had long-term facial function of HB I or II. Those patients who had a positive intraoperative response to facial nerve stimulation had good long-term facial function. Facial function declined in some patients after postoperative radiation or revision surgery.

\section{Discussion}

Surgical exposure of petroclival meningiomas has long been considered a challenge for skull base surgeons; in fact, they were historically considered unresectable. ${ }^{8}$ Most surgeons today use the TO approach to provide access to smaller tumors in this location, but the TC with facial nerve rerouting 
Table 1 Presenting symptoms

\begin{tabular}{|c|c|c|c|c|c|c|c|}
\hline Patient & Headache & Hearing loss & Tinnitus & Vertigo/imbalance & Ataxia & Cranial neuropathy & Extremity weakness \\
\hline 1 & & & & & 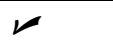 & VII & \\
\hline \multicolumn{8}{|l|}{2} \\
\hline 3 & & V & & レ & & & \\
\hline 4 & & & & $\nu$ & & IX & $レ$ \\
\hline 5 & & レ & & $\nu$ & & $\mathrm{V}$ & \\
\hline 6 & & $\nu$ & & & レ & $\mathrm{VI}$ & \\
\hline 7 & & $r$ & & レ & & $\mathrm{V}$ & \\
\hline 8 & レ & 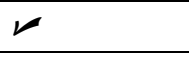 & & V & & IX & \\
\hline 9 & & & & & & $\mathrm{~V}, \mathrm{VII}$ & \\
\hline 10 & & & & レ & & & \\
\hline 11 & $\nu$ & & & レ & & V & レ \\
\hline 12 & & $\nu$ & & & & $\mathrm{V}$ & \\
\hline 13 & 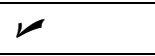 & $\nu$ & $レ$ & & & & \\
\hline 14 & & $\nu$ & レ & & & & \\
\hline 15 & & $r$ & & & & & \\
\hline 16 & & $\nu$ & & & & V & \\
\hline
\end{tabular}

Table 2 Complication and postoperative course

\begin{tabular}{|c|c|c|c|c|}
\hline Patient & Cranial neuropathies & Other complications & Revision surgery (reason) & Postoperative radiation \\
\hline 1 & V & Hydrocephalus, CVS & Yes (tumor regrowth) & \\
\hline 2 & & Meningitis/death & No & \\
\hline 3 & $\mathrm{~V}, \mathrm{VI}$ & & No & \\
\hline 4 & III-VI (partial) & & No & レ \\
\hline 5 & $\mathrm{~V}, \mathrm{VI}$ & & No & レ \\
\hline 6 & $\mathrm{~V}, \mathrm{VI}$ & Tympanic perforation & No & $レ$ \\
\hline 7 & & & No & \\
\hline 8 & & Tracheostomy/PEG & Yes (tumor regrowth) & レ \\
\hline 9 & & $\begin{array}{l}\text { Reexpansion edema; } \\
\text { tracheostomy/PEG }\end{array}$ & No & $レ$ \\
\hline 10 & IV & $\begin{array}{l}\text { Reexpansion edema/ } \\
\text { small brainstem hemorrhage }\end{array}$ & No & \\
\hline 11 & & $\begin{array}{l}\text { Corneal hypesthesia; } \\
\text { keratoconjunctivitis }\end{array}$ & No & \\
\hline 12 & $\mathrm{VI}$ & & No & \\
\hline 13 & IV & & No & \\
\hline 14 & & & No & $\boldsymbol{\nu}$ \\
\hline 15 & & CSF leak & Yes (CSF leak) & \\
\hline 16 & & $\begin{array}{l}\text { Reexpansion edema, } \\
\text { transient hemiparesis }\end{array}$ & No & \\
\hline
\end{tabular}

Abbreviations: CSF, cerebrospinal fluid; CVS, cerebral vasospasm; PEG, percutaneous endoscopic gastrostomy. 

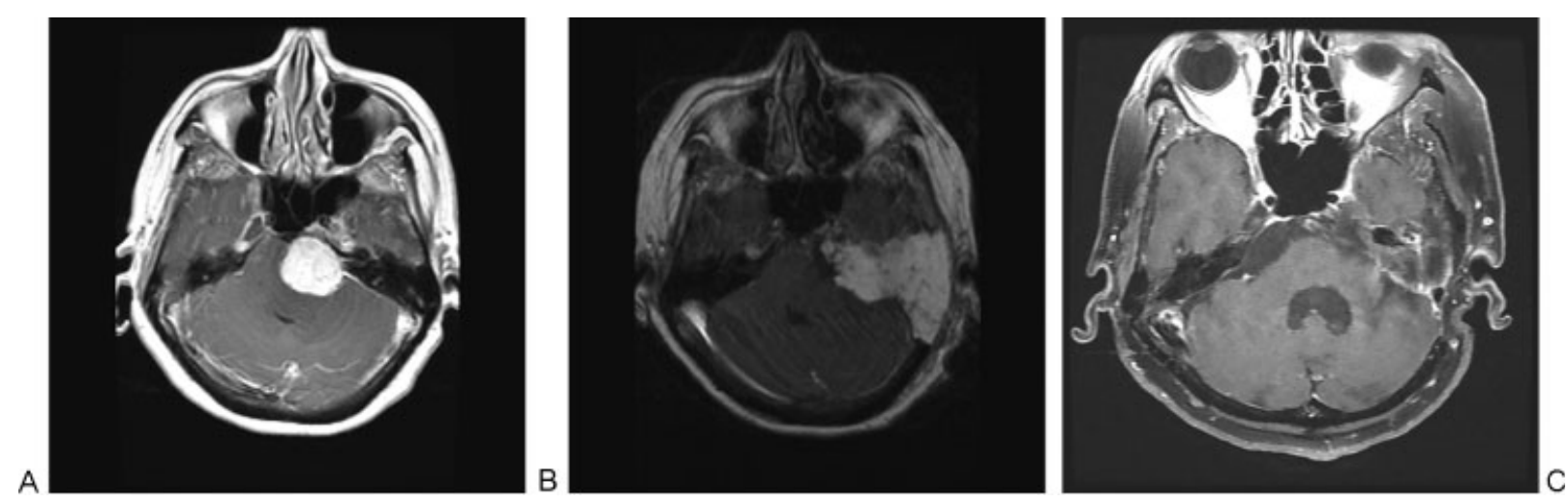

Fig. 1 Patient with a 3.5-cm left petroclival meningioma excised by an extended translabyrinthine approach (subtotal resection as tumor capsule left on brainstem). (A) Preoperative T1-weighted magnetic resonance imaging (MRI) with gadolinium. (B) Immediate postoperative T1-weighted MRI with gadolinium. (C) A 5-year postoperative fat-saturated T1-weighted MRI with gadolinium.
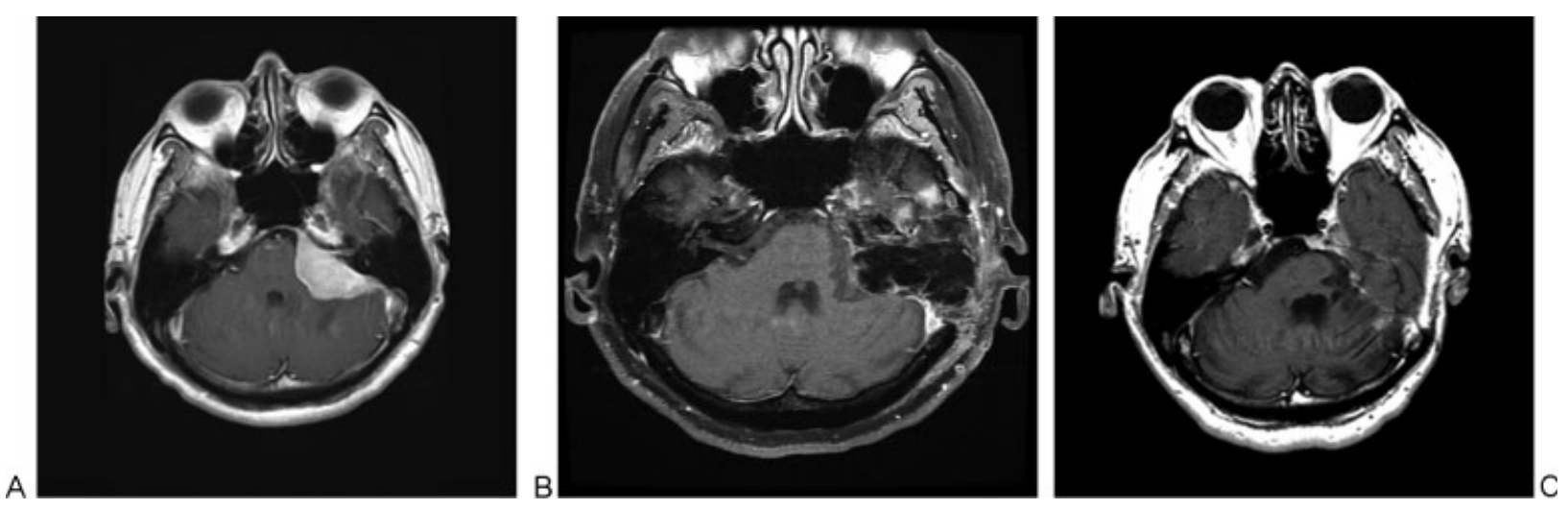

Fig. 2 Patient with a 5.1-cm left petroclival meningioma excised by an extended translabyrinthine approach (gross total resection). (A) Preoperative T1-weighted magnetic resonance imaging (MRI) with gadolinium. (B) A 3-month postoperative fat-saturated T1-weighted MRI with gadolinium. (C) A 3.5 year postoperative T1-weighted MRI with gadolinium.

is required for larger lesions. These approaches have varying reported degrees of long-term facial nerve dysfunction in the literature.

In a retrospective review of skull base lesions extending to the petrous apex approached TO or TC, De la Cruz and Teufert reviewed 40 patients who underwent a TO or TC approach, with average tumor sizes of $2.4 \mathrm{~cm}$ and $4.4 \mathrm{~cm}$, respectively. ${ }^{3}$ They report that $42 \%$ of patients had normal facial function (HB I) at the time of discharge; $55 \%$ of patients had normal facial function at long-term follow-up. However, in that study, 8 of 10 patients who underwent a TC approach had facial function graded as a $\mathrm{HB} \mathrm{VI}$, or complete paralysis, at the time of discharge. Of these patients, only one recovered to a HB II or better at long-term follow-up. Although the TO approach preserves facial nerve function, it provides adequate exposure only for smaller tumors; the TC approach has improved exposure but shows definitively worse facial nerve outcomes.

Other approaches to petroclival meningiomas have also been described including transzygomatic extended middle fossa, ${ }^{9}$ far-lateral transcondylar, ${ }^{8}$ extended middle fossa, ${ }^{10}$ transpetrosal-transtentorial, ${ }^{11}$ and a standard retrosigmoid approach. Each of these carries its own advantages and disadvantages, offering varying degrees of exposure and requiring different levels of brain retraction. As discussed later, the EXTL approach allows good exposure of the anterior petrous apex, and as with the translabyrinthine approach, it avoids significant brain retraction. Baugh et al also describe a combined middle fossa/retrolabyrinthine approach that allows for hearing preservation, although their average tumor size was smaller than the average reported here $(3.1 \mathrm{~cm}$ as opposed to $4.6 \mathrm{~cm}) .^{12}$

In the current study, the EXTL approach allowed for gross total resection in 6 of 10 patients. In patients with subtotal resection, tumor was left behind because it was adherent to vital structures or extended through the foramen magnum or into Meckel's cave. Only 2 of 16 patients required reoperation for tumor residua/regrowth, and 6 underwent postoperative radiation. This is comparable with revision surgery rates with the TC approach, as in De la Cruz and Teufert's review, where 1 of 13 patients required revision surgery for tumor regrowth. ${ }^{3}$ Although these authors report a $93.3 \%$ rate of gross total removal with the TC approach and a $92 \%$ rate with the TO approach, their patient population is disparate from ours (including patients with acoustic neuromas). Bambakidis et al report a rate of gross total resection closer to ours (43\%) in their review of 46 patients who underwent various approaches for resection of petroclival meningiomas. ${ }^{13}$ Angeli et al report a high rate of gross total 
Table 3 Facial nerve outcomes

\begin{tabular}{|c|c|c|c|c|c|c|c|c|}
\hline Patient & $\begin{array}{l}\text { Preoperative } \\
\text { function }\end{array}$ & $\begin{array}{l}\text { Intraoperative } \\
\text { stimulation }\end{array}$ & $\begin{array}{l}\text { CN VII } \\
\text { cut }\end{array}$ & $\begin{array}{l}\text { Immediate } \\
\text { postoperative }\end{array}$ & $\begin{array}{l}\text { 2-4 wk } \\
\text { postoperative }\end{array}$ & $\begin{array}{l}\text { Long-term } \\
\text { function }\end{array}$ & $\begin{array}{l}\text { Follow-up, } \\
\text { mo }\end{array}$ & $\begin{array}{l}\text { Other treatment } \\
\text { (facial function) }\end{array}$ \\
\hline 1 & HB II & Negative & & & & & & Reoperation \\
\hline \multicolumn{9}{|l|}{2} \\
\hline 3 & $\mathrm{HB}$ I & & & $\mathrm{HB}$ VI & HB III & $\mathrm{HBI}$ & 17 & \\
\hline 4 & $\mathrm{HB}$ I & Positive & & & HB VI & $\mathrm{HB}$ I & 32 & XRT (HB II) \\
\hline 5 & $\mathrm{HB} \mathrm{I}$ & & & & $\mathrm{HB} \mathrm{V}$ & HB II & 22 & XRT \\
\hline 6 & $\mathrm{HBI}$ & & Yes & & & $\mathrm{HB}$ VI & 11 & XRT \\
\hline 7 & $\mathrm{HB} \mathrm{I}$ & Positive & & & HB III & HB IV & 92 & \\
\hline 8 & HB II & & & & & $\mathrm{HBI}$ & 54 & $\begin{array}{l}\text { Reoperation } \\
\text { (HB II); XRT }\end{array}$ \\
\hline 9 & HB II & & Yes & & & $\mathrm{HB} \mathrm{VI}$ & 61 & XRT \\
\hline 10 & $\mathrm{HBI}$ & Positive & & & & & & \\
\hline 11 & $\mathrm{HB} \mathrm{I}$ & Positive & & & HB II & $\mathrm{HBI}$ & 53 & \\
\hline 12 & $\mathrm{HBI}$ & Positive & & $\mathrm{HB} \mathrm{I}$ & $\mathrm{HBI}$ & $\mathrm{HBI}$ & 47 & \\
\hline 13 & HB I & & & $\mathrm{HB} \mathrm{I}$ & $\mathrm{HB} \mathrm{I}$ & $\mathrm{HB}$ I & 38 & \\
\hline 14 & $\mathrm{HB} I$ & Positive & & & HB III & $\mathrm{HB}$ I & 29 & $\begin{array}{l}\text { XRT (increased } \\
\text { weakness) }\end{array}$ \\
\hline 15 & $\mathrm{HBI}$ & Positive & & HB II & $\mathrm{HB} \mathrm{VI}$ & HB II & 14 & Reoperation \\
\hline 16 & $\mathrm{HB}$ I & Positive & & HB I & HB II & $\mathrm{HB} I$ & 3 & \\
\hline
\end{tabular}

Abbreviations: CN, cranial nerve; HB, House-Brackmann grade; mo, months; XRT, radiotherapy.

resection (82\%) in their series of 24 tumors of varied histology approached either TO or TC, but these tumors were of varied histology, and some patients required a second stage for residual tumor. ${ }^{14}$ The recurrence rate is $11 \%$ in their series. The follow-up time in the current study (36.4 months) is comparable with those reported in the literature, $3,14,15$ as is our reoperation rate. The strict definition of gross total resection used in this study may inflate the number of patients in the subtotal category. In fact, - Fig. 1A shows a subtotal resection (tumor capsule left on brainstem) in which the immediate postoperative and 5-year postoperative MRIs show no tumor. These results demonstrate that the EXTL approach provides adequate exposure for optimal resection of petroclival tumors.

The EXTL approach has been described for surgical access to very large acoustic neuromas. ${ }^{16}$ Gurgel et al report that the EXTL approach has poorer facial nerve outcomes than either the translabyrinthine or retrosigmoid approach in a metaanalysis of acoustic neuroma patients, but they point out that this is likely a selection bias because the EXTL approach is reserved for much larger tumors. ${ }^{16}$ As described earlier, patients with petroclival meningiomas have been reported in some series to have worse long-term facial function than other tumors of the anterior cerebellopontine angle and petroclival junction. In a retrospective study of 50 patients who underwent different surgical approaches to petroclival meningiomas, $44 \%$ of patients had new $\mathrm{CN}$ deficits after surgery, and $20 \%$ had facial weakness. ${ }^{8}$ These deficits were determined to be transient by follow-up examinations in only $41 \%$ of patients.
The TC approach generally leads to poorer facial nerve function overall than reported in this study because of nerve rerouting. As described earlier, De la Cruz and Teufert show a HB I or II in only one of eight patients undergoing a TC approach, ${ }^{3}$ and five of these underwent facial nerve neurorrhaphy. Although some reports show better results with TC facial nerve outcomes, such as Angeli's 60\% HB III or better at long-term follow-up after the TC approach, rerouting the nerve nearly always results in transient facial dysfunction (95\% of patients). ${ }^{14}$ Devèze et al describe 43 patients who underwent transpetrosal resection of meningiomas with $73 \%$ achieving HB I or II; however, most of these patients underwent widened retrolabyrinthine and translabyrinthine approaches without rerouting of the facial nerve. ${ }^{15}$ Although the two patients who required CN VII to be cut at surgery in the current study had a HB VI at long-term follow-up (-Table 3), the remaining 10 of 11 patients with long-term follow-up data were graded as HB I or II. The EXTL approach for resection of petroclival meningiomas has superior facial nerve outcomes than the TC approach in the immediate postoperative period as well as in long-term follow-up. As shown in - Table 3, a robust response on intraoperative facial nerve monitoring was a favorable prognostic sign. It is not surprising that facial nerve function declines with further surgery or radiation therapy.

The presenting symptoms and complications in this study are consistent with those in the literature. Perturbation of balance, hearing loss, headache, and tinnitus are commonly described symptoms for lesions in this location., 6,15,17 Brain edema, hydrocephalus, meningitis, among other complications, 
have been reported with other approaches, such as the TC approach, 6,14 and they are equivalent to the findings reported here. $\mathrm{CN}$ dysfunction other than the facial nerve are not uncommon, with diplopia especially prevalent, as in this study. $^{3,14,15}$

Although the current study is limited by its retrospective nature and a limited number of patients, it provides a convincing representation of patients treated successfully with the EXTL approach for petroclival meningiomas. The EXTL approach has similar reoperation rates as the TC approach and does not require rerouting of the facial nerve. The avoidance of facial nerve rerouting affords improved immediate and long-term facial nerve function compared with the TC approach.

\section{Conclusion}

The EXTL approach should be considered for meningiomas involving the anterior cerebellopontine angle and petroclival junction. Although larger studies of the EXTL approach are needed to further define its outcomes, the current study demonstrates that the EXTL approach provides superior preservation of facial nerve function compared with the TC approach.

\section{References}

1 De la Cruz A. Transcochlear approach to lesions of the cerebellopontine angle and clivus. Rev Laryngol Otol Rhinol (Bord) 1981; 102(1-2):33-36

2 Fisch U, Pillsbury HC. Infratemporal fossa approach to lesions in the temporal bone and base of the skull. Arch Otolaryngol 1979; 105(2):99-107

3 De la Cruz A, Teufert KB. Transcochlear approach to cerebellopontine angle and clivus lesions: indications, results, and complications. Otol Neurotol 2009;30(3):373-380
4 House WF, Hitselberger WE. The transcochlear approach to the skull base. Arch Otolaryngol 1976;102(6):334-342

5 Jackler RK. Lateral approaches to the internal auditory canal and cerebellopontine angle. In: Jackler RK, ed. Atlas of Skull Base Surgery and Neurotology. 2nd ed. New York, NY: Thieme; 2009:53-57

6 Thedinger BA, Glasscock ME III, Cueva RA. Transcochlear transtentorial approach for removal of large cerebellopontine angle meningiomas. Am J Otol 1992;13(5):408-415

7 House JW, Brackmann DE. Facial nerve grading system. Otolaryngol Head Neck Surg 1985;93(2):146-147

8 Nanda A, Javalkar V, Banerjee AD. Petroclival meningiomas: study on outcomes, complications and recurrence rates. J Neurosurg 2011;114(5):1268-1277

9 Zhao JC, Liu JK. Transzygomatic extended middle fossa approach for upper petroclival skull base lesions. Neurosurg Focus 2008; 25(6):E5; discussion E5

10 Bochenek Z, Kukwa A. An extended approach through the middle cranial fossa to the internal auditory meatus and the cerebellopontine angle. Acta Otolaryngol 1975;80(5-6):410-414

11 Hakuba A, Nishimura S, Jang BJ. A combined retroauricular and preauricular transpetrosal-transtentorial approach to clivus meningiomas. Surg Neurol 1988;30(2):108-116

12 Baugh A, Hillman TA, Shelton C. Combined petrosal approaches in the management of temporal bone meningiomas. Otol Neurotol 2007;28(2):236-239

13 Bambakidis NC, Kakarla UK, Kim LJ, et al. Evolution of surgical approaches in the treatment of petroclival meningiomas: a retrospective review. Neurosurgery 2007;61(5, Suppl 2):202-209; discussion 209-211

14 Angeli SI, De la Cruz A, Hitselberger W. The transcochlear approach revisited. Otol Neurotol 2001;22(5):690-695

15 Devèze A, Franco-Vidal V, Liguoro D, Guérin J, Darrouzet V. Transpetrosal approaches for meningiomas of the posterior aspect of the petrous bone: results in 43 consecutive patients. Clin Neurol Neurosurg 2007;109(7):578-588

16 Gurgel RK, Dogru S, Amdur RL, Monfared A. Facial nerve outcomes after surgery for large vestibular schwannomas: do surgical approach and extent of resection matter? Neurosurg Focus 2012; 33(3):E16

17 Samii M, Tatagiba M. Experience with 36 surgical cases of petroclival meningiomas. Acta Neurochir (Wien) 1992;118(1-2):27-32 